\title{
Postoperative Outcomes in Coblation versus Electrocautery Tonsillectomies
}

\author{
Viet Pham ${ }^{1}$, Nikunj Rana ${ }^{2 *}$, Michael Underbrink ${ }^{1}$, Farrah Siddiqui ${ }^{1}$, \\ Shraddha Mukerji ${ }^{1}$, Harold Pine ${ }^{1}$ \\ ${ }^{1}$ Department of Otolaryngology, The University of Texas Medical Branch in Galveston, Galveston, USA \\ ${ }^{2}$ School of Medicine, The University of Texas Medical Branch in Galveston, Galveston, USA \\ Email: "narana@utmb.edu
}

Received November 17, 2013; revised December 15, 2013; accepted January 2, 2014

Copyright (c) 2014 Viet Pham et al. This is an open access article distributed under the Creative Commons Attribution License, which permits unrestricted use, distribution, and reproduction in any medium, provided the original work is properly cited. In accordance of the Creative Commons Attribution License all Copyrights (C) 2014 are reserved for SCIRP and the owner of the intellectual property Viet Pham et al. All Copyright (C) 2014 are guarded by law and by SCIRP as a guardian.

\begin{abstract}
Purpose: To investigate whether children undergoing a tonsillectomy or adenotonsillectomy (AT) with Coblation $^{\circledR}$ will experience less postoperative pain and return to a normal diet and a regular activity level sooner compared to the same procedure using electrocautery dissection. This may manifest less school and work missed by the child and caregiver, respectively. Materials and Methods: Seventy-four children between the ages 2 - 13 years with either obstructive sleep apnea or chronic tonsillitis were recruited at a single tertiary-care center from January 2011 to November 2012 and underwent an AT via electrocautery or Coblation ${ }^{\circledR}$. Caregivers were given a ten-point Wong-Baker FACES pain scale and questions inquiring the degree of oral intake, activity level, and impact on both the child and caregiver in regards to missing work or school on postoperative days (POD) $0,1,2$, 3, 5, 7, and 14. Results: Children in the Coblation ${ }^{\circledR}$ arm required less pain medications $(\mathbf{p}<0.0022)$ and improved drinking subjectively $(p<0.0049)$ on POD 0 . Subsequent results were not significantly different for any other day. Age- and gendered-controlled multivariate analysis revealed a statistically significant difference in pain medications administered $(p<0.0001)$ but not pain scores $(p<0.2115)$ between the two techniques, although this difference in medications is likely related to the results observed on POD 0 . There was no incidence of postoperative hemorrhage in either group. Conclusions: While there was less pain medication administered and slightly improved oral intake of liquids on POD 0 for children in the Coblation ${ }^{\circledR}$ arm, there was no difference in subsequent postoperative outcome or hemorrhage rates.
\end{abstract}

\section{KEYWORDS}

Postoperative Outcomes; Coblation; Electrocautery; Tonsillectomies; Pediatric

\section{Introduction}

Adenotonsillectomies (AT) are regarded as one of the most common pediatric surgical procedures performed in the United States yearly, typically tasked to treat sleeprelated breathing disorders attributed to tonsillar and adenoid hypertrophy or to alleviate the impaired quality of life associated with recurrent tonsillitis. Removing tonsillar tissue has conventionally been carried out using monopolar electrocautery, as its inherent superiority in hemostasis has helped it replace cold dissection techniques historically employed. There have been numerous

*Corresponding author. documented accounts and anecdotal experiences of patient intolerance to postoperative pain, odynophagia, dysphagia, and subsequent dehydration with this surgical technique. This is not surprising considering the thermal damage subjected to adjacent tissues in light of local temperatures anywhere between $400^{\circ} \mathrm{C}-600^{\circ} \mathrm{C}$ generated from direct contact between the electrode and the tissue [1].

First introduced as a viable surgical modality in 1998, another technique by which to perform AT utilizes plasma-mediated tissue ablation. Commonly referred to as Coblation ${ }^{\circledR}$, this process involves passing a bipolar radiofrequency current through isotonic saline to convert 
it into an ionized plasma layer [2]. This layer effectively disrupts intercellular molecular bonds in the tissues resulting in a vaporization effect [3]. Surface irrigation and suction are applied to prevent significant pooling of saline inside the oral cavity [4]. Coblation ${ }^{\circledR}$ generates a substantially lower thermal effect compared to electrocautery, estimated between $45^{\circ} \mathrm{C}-85^{\circ} \mathrm{C}$, with a subsequent presumption of diminished collateral thermal damage to surrounding tissues [5]. As such, this decreased heat transfer is believed to translate clinically to the experience of less postoperative morbidity. No point during the procedure of the coblative energy is introduced into the body as the process is focused only on the electrodes.

There are a myriad of studies that have delved into comparing postoperative outcomes based on the surgical technique implemented to perform adenotonsillectomies. Table 1 displays a number of those that convey an advantage to Coblation ${ }^{\circledR}$ over other modalities, while Table 2 presents a comparable number of studies that contrast with these notions.

The recent introduction of Coblation ${ }^{\circledR}$ relative to other techniques prompted evaluations into whether or not there was an association with an increased amount of adverse events. One of the most common complications to tonsillectomies is postoperative bleeding. Table 3 presents studies that have investigated differences in postoperative hemorrhage with coblator tonsillectomies.

This array of conflicting results is best summarized by a review in the Cochrane Database, which concluded that there was insufficient evidence to determine the superiority of coblator tonsillectomies over other techniques, although the authors did mention that most of the analyzed studies were of low-quality that precluded a metaanalysis [22]. Consequently, the pertinence of this investigation is with its intention to further elucidate posttonsillectomy outcomes with Coblation ${ }^{\circledR}$ compared to monopolar electrocautery in the pediatric population. While examining commonly assessed variables such as pain levels, narcotic pain medication use, and resumption of a regular diet and activity level, this trial also monitored the recovery course's impact on the children's caregivers, keeping in mind that evaluating parental return

Table 1. Past investigations favoring coblator adenotonsillectomies.

\begin{tabular}{|c|c|c|c|c|}
\hline Study & $\begin{array}{c}\text { Comparative } \\
\text { Technique }\end{array}$ & $\begin{array}{c}\text { Size } \\
\text { (age range) }\end{array}$ & $\begin{array}{l}\text { Measured } \\
\text { POD }\end{array}$ & Conclusions \\
\hline Temple (2001) [6] & Bipolar & 38 (4 - 12 yrs $)$ & $1-9$ & Decreased pain \\
\hline Stoker (2004) [7] & Monopolar & 89 (3 - 12 yrs) & $1-14$ & Decreased nausea, vomiting, \& physician calls \\
\hline Chang* (2005) [8] & Monopolar & 101 (2 - 16 yrs $)$ & $1,3,5$ & $\begin{array}{l}\text { Decreased pain medications on POD5 } \\
\text { Improved oral intake and activity level }\end{array}$ \\
\hline Parsons (2006) [9] & $\begin{array}{l}\text { Harmonic Scalpel, } \\
\text { Monopolar }\end{array}$ & $61(3-12$ yrs $)$ & $1-10$ & Decreased pain compared to harmonic scalpel \& monopolar \\
\hline Mitic (2007) [10] & $\begin{array}{l}\text { Cold dissection } \\
\text { with bipolar }\end{array}$ & $40(4-12$ yrs $)$ & $1-10$ & $\begin{array}{l}\text { Decreased pain \& pain medications Improved oral } \\
\text { intake \& activity level Shorter recovery time by } 2 \text { days }\end{array}$ \\
\hline Di Rienzo (2008) [11] & Cold dissection & $42(5-16$ yrs $)$ & $1-14$ & $\begin{array}{l}\text { Decreased pain \& pain medications } \\
\text { Quicker resumption of regular diet \& return to school }\end{array}$ \\
\hline Parker (2011) [3] & Monopolar & 80 ( $\leq 18$ yrs $)$ & $1-14$ & $\begin{array}{l}\text { Decreased pain } \\
\text { Quicker resumption of regular diet }\end{array}$ \\
\hline Paramasivan (2012) [13] & Monopolar & 50 (5 - 12 yrs $)$ & 0,4 & Decreased pain \\
\hline
\end{tabular}

"Intracapsular Coblation ${ }^{\circledR}$ tonsillectomy.

Table 2. Past investigations not favoring coblator adenotonsillectomies.

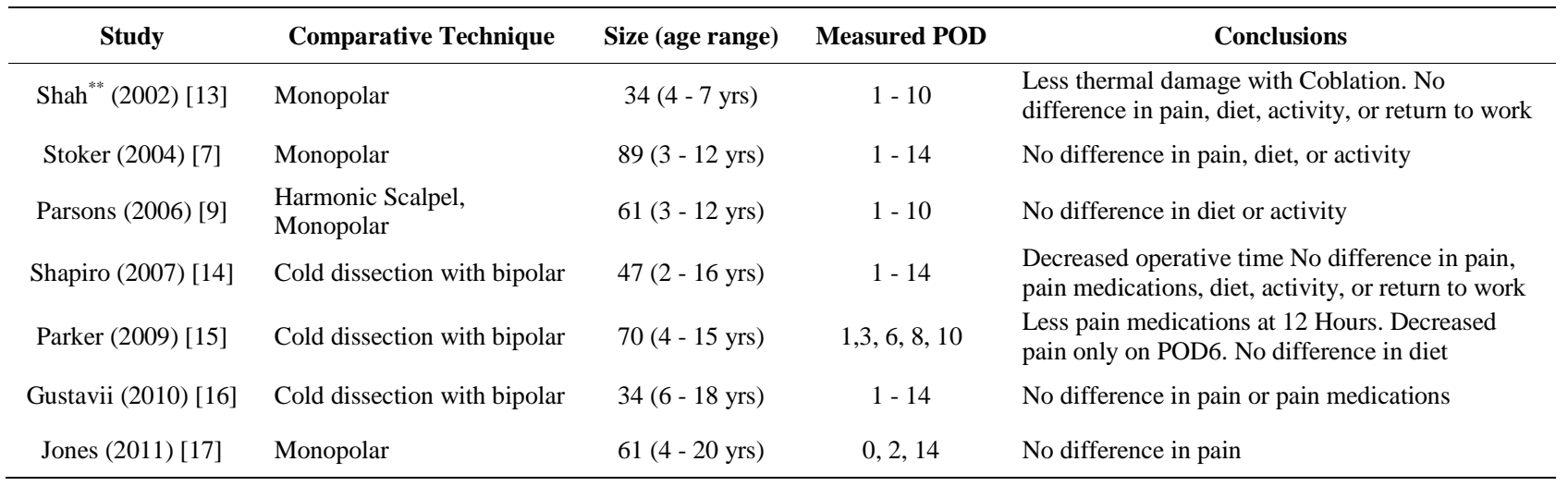

${ }^{* *}$ Trial aborted secondary to airway obstruction in Coblation ${ }^{\circledR}$ group. 
Table 3. Past investigations comparing coblator post-operative hemorrhage rates with other techniques.

\begin{tabular}{|c|c|c|c|c|}
\hline Study & Comparative Technique & Size & Population & Conclusions \\
\hline Temple (2001) [6] & Bipolar electocautery & 38 & Children & No difference \\
\hline Timms (2002) [5] & Bipolar electrocautery & 10 & Adults & No difference \\
\hline Noon (2003) [18] & Cold dissection with bipolar & 65 & Adults & Increased hemorrhage \\
\hline Belloso (2003) [19] & Bipolar electrocautery & 1587 & Adults and Children & No difference \\
\hline Lowe (2004) [20] & $\begin{array}{l}\text { Cold dissection, } \\
\text { Cold dissection with monopolar or bipolar electrocautery }\end{array}$ & 11,796 & Adults and Children & Increased Hemorrhage \\
\hline Divi (2005) [21] & Non-coblation tonsillectomy & 1762 & $\mathrm{n} / \mathrm{a}$ & No difference \\
\hline
\end{tabular}

n/a not available.

to work has only been briefly mentioned by a few other studies $[8,13]$.

\section{Methods}

Children aged between 2 and 13 years undergoing tonsillectomy or AT for recurrent tonsillitis, sleep-disordered breathing, or obstructive sleep apnea were selected between January 2011 and November 2012 at a tertiary care hospital in a single blinded fashion to have the procedure performed via monopolar electrocautery or Coblation $^{\circledR}$ (ArthoCare ENT). All procedures were performed with complete excision of the tonsils using subcapsular dissection regardless of which technique was utilized. Within the confines of informed consent the study remained single blinded. While caregivers were informed of the technique their child would undergo, there was no indication as to whether the post-operative course would vary given either technique. The surgeries were performed by resident physicians with close monitoring and assistance from one of two fellowship-trained pediatric faculty members from the Department of Otolaryngology at The University of Texas Medical Branch in Galveston (UTMB) who conducted ATexclusively with one technique.

Exclusion criteria included a history of a peritonsillar abscess, major medical problems or co-morbidities, congenital abnormalities, or acute tonsillar infection in the past three weeks prior to surgery. In addition, children undergoing concurrent surgical procedures, such as myringotomy with tympanostomy tube insertion, were excluded to help maintain similar operative times among all of the subjects. The one exception to this was if there were plans to undergo cerumenectomies as this was felt to not significantly lengthen the overall operative time.

For those selected to undergo dissection with electrocautery, tonsillectomies were carried out at settings of 15 and 12 for the cut and coagulation functions, respectively. Adenoidectomy was performed with the suction mo- nopolar electrocautery at a setting of 35 for coagulation without employing the cut function. Coblation ${ }^{\circledR}$ tonsillectomies were done at settings of 7 and 3 for coblator and coagulation, respectively, with an increase in the coblator setting to 9 but the same level for coagulation when conducting the adenoidectomy.

After much collaboration, the UTMB Department of Anesthesia had formulated a preset protocol for preoperative, perioperative, and immediate postoperative anesthesia. A copy of this protocol is attached as Appendix at the end of this submission.

Subjects received a one-time intraoperative doses of ampicillin $50 \mathrm{mg} / \mathrm{kg}$ (up to $500 \mathrm{mg}$ ) and dexamethasone $0.5 \mathrm{mg} / \mathrm{kg}$ (up to $10 \mathrm{mg}$ ), but clindamycin $10 \mathrm{mg} / \mathrm{kg}$ (up to $300 \mathrm{mg}$ ) was substituted for ampicillin in cases of drug allergy. All patients were discharged home with a seven day-regimen of amoxicillin $50 \mathrm{mg} / \mathrm{kg} / \mathrm{d}$ divided in twicedaily dosing along with Tylenol with codeine $1 \mathrm{mg} / \mathrm{kg}$ every four hours as needed. A ten day-regimen of Omnicef $14 \mathrm{mg} / \mathrm{kg} / \mathrm{d}$ divided into twice-daily dosing was substituted for cases of amoxicillin allergy. Azithromycin 12 $\mathrm{mg} / \mathrm{kg}$ daily for five days was substituted in cases of anaphylactic reactions to cephalosporins.

Postoperative outcomes were obtained in a single blinded fashion via answers to a survey administered to the subject's caregiver. This included a combination of the Wong-Baker FACES (REF) pain scale and a set of questions-adapted from questionnaires as detailed by Chang and Myatt-in order to evaluate a child's return to normal diet and activity, pain level, and amount of analgesia used throughout the day (Figure 1) [8,23]. In addition, caregivers were also asked how their daily activity was affected by their child's recovery course. The caregivers filled out identical copies of this survey on POD 0 , $1,2,3,5,7$, and 14. Other variables accounted for, but not addressed in the survey itself, included postoperative complications such as bleeding, dehydration, or any other condition that would warrant emergent evaluation or hospital admission (Figure 1). 
Date:

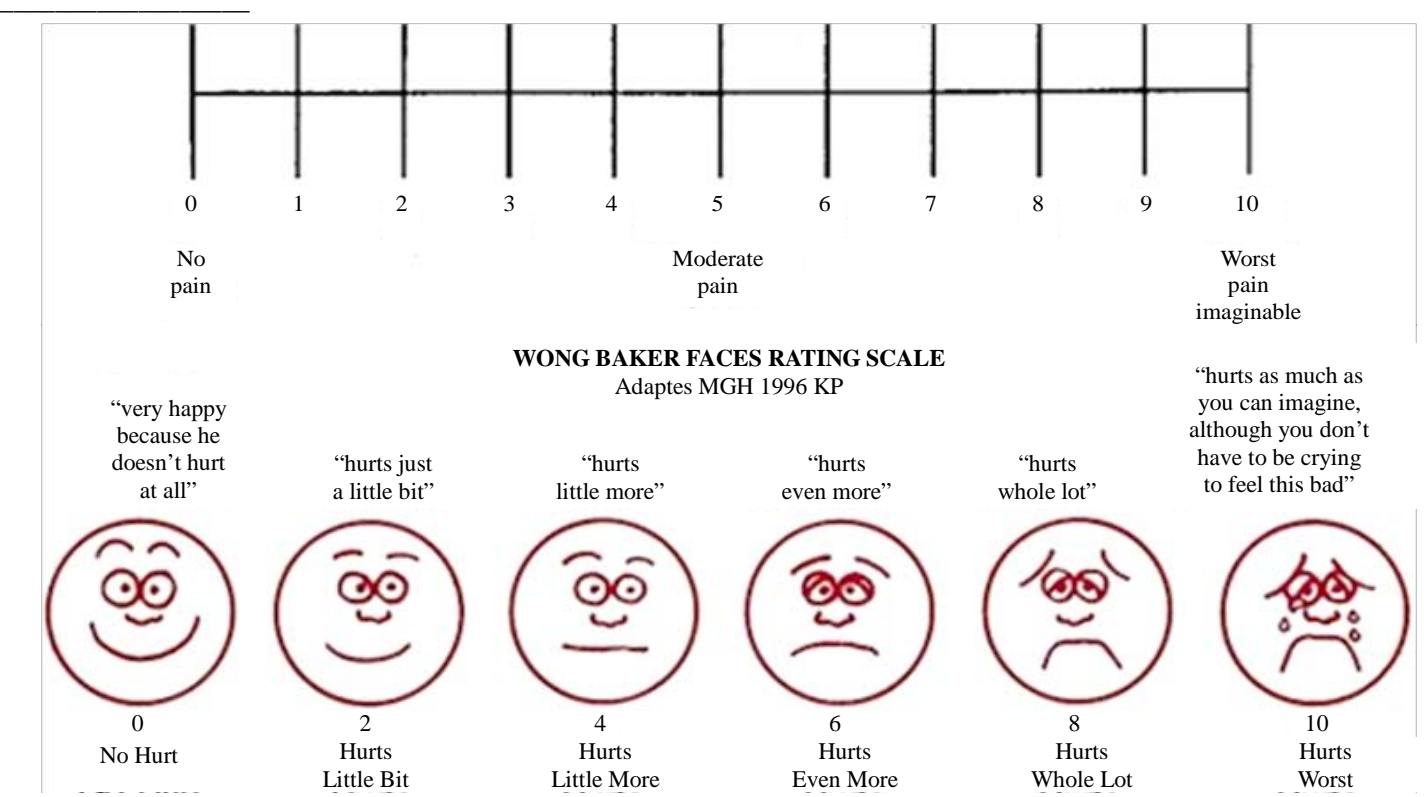

Administer this pain scale when you arrive home from the hospital. Faces are given numbers from 0 to 10 . The face on the far left has a number score of 0 , the next face has a score of 2 and so on. If the face score is equal to 4 or higher, give your child a dose of pain medication. Always check to see if the pain was relieved by re-administering the scale 30 minutes after each dose of pain medication. Be sure to record all pain scores and pain medication given for that day.

Check your child's pain level using this scale at least once every four hours throughout the day. If your child appears to be in pain at any other time, administer the scale right away and give pain medication if needed. Check your child's score right before he or she goes to bed as well.

\begin{tabular}{ccc}
\hline Time & Pain Score & Amount of Pain Medication Given \\
\hline
\end{tabular}

Has your child been drinking?

A. Not at all

B. Sips reluctantly when encouraged

C. Sips on their own

D. Drinking as usual

Has your child been eating?
A. Not at all
B. A few mouthfuls
C. Eating less than normal
D. Eating normally

What kind of foods has your child been eating?

A. Has not been eating

B. Juices and fluids

C. Soft foods

D. Regular diet

Has your child been talking?

A. Not at all

B. A few words quietly

C. In a normal voice but less talkative than usual

D. Talking as usual

Has your child been active?

A. No, lying in bed

B. Reluctant to sit up in bed

C. Sitting up in bed

D. Getting out of bed
Has your child been playing?
A. Not at all
B. Playing in bed
C. Getting up to watch others
D. Getting up to play

How has your child's mood been?
A. Silent
B. Unhappy and miserable
C. A little upset
D. Content, cheerful

Did your child have to miss school/daycare

today?

A. Yes

B. No

C. Does not attend school/daycare

Did you have to miss work today?
A. Yes
B. No
C. Would not have worked anyway

Were you able to complete all of your planned activities and errands for today?
A. Yes
B. Some of them
C. No
D. I did not have an

Figure 1. Postoperative survey. 
Instructions to caregivers were clearly listed within the survey to maintain consistency in postoperative recordings.

Statistical analysis employed a number of endeavors given the various data points measured. A paired t-test compared age, average pain scores, and amount of medications administered. A Chi-squared test assessed for gender differences between the two study groups, while a Chi-squared test and a Mann-Whitney $\mathrm{U}$ test were utilized to analyze the responses to the survey questions. A repeated measures analysis using Statistical Analysis Software $\left(\mathrm{SAS}^{\circledR}\right.$ ) evaluated for trends in the pain scores and pain medications given over time.

\section{Results}

A total of 195 patients were initially enrolled, with 112 in the Coblation ${ }^{\circledR}$ arm and 83 in the electrocautery arm. Despite efforts to secure compliance with survey responses and ensure continued follow up, there remained a 2:1 size discrepancy between the Coblation ${ }^{\circledR}$ and electrocautery groups, respectively. 52 Coblation ${ }^{\circledR}$ subjects and 22 electrocautery subjects returned with completed survey responses for a total study size of 74. At baseline, denoted as POD 0 in this study, there were no differences between the two groups in regards to gender, age, or average pain score. However, children who underwent a coblator AT required less number of pain medications than their electrocautery counterparts at baseline (2.27 vs. 3.64, $\mathrm{p}=0.0022$ ). These results are presented in Table 4. No statistically significant differences in pain scores or medication use were observed during any other postoperative day.

With respect to pain scores, a multivariate analysis did not reveal a difference in regards to technique, age, or gender as noted in Table 5. A repeated measures analysis

Table 4. Baseline results on POD0.

\begin{tabular}{lccc}
\hline & $\begin{array}{c}\text { CAUTERY } \\
(\mathrm{n}=22)\end{array}$ & $\begin{array}{c}\text { COBLATION } \\
(\mathrm{n}=52)\end{array}$ & p-value \\
\hline Female Male & $\begin{array}{c}8(36.4 \%) \\
14(63.6 \%)\end{array}$ & $\begin{array}{c}21(40.4 \%) \\
31(59.6 \%)\end{array}$ & 0.7460 \\
$\begin{array}{l}\text { Age, years } \\
\text { Range: } 2-12 \\
\text { (mean, std dev) }\end{array}$ & $5.36(2.52)$ & $6.54(2.81)$ & 0.0948 \\
$\begin{array}{l}\text { Pain Score } \\
\text { (mean, std dev) }\end{array}$ & $6.09(3.01)$ & $5.32(2.43)$ & 0.2476 \\
$\begin{array}{l}\text { Pain Medications } \\
\text { (mean, std dev) }\end{array}$ & $3.64(1.73)$ & $2.27(1.19)$ & 0.0022 \\
\hline
\end{tabular}

Table 5. Multivariate analysis of pain scores.

\begin{tabular}{cccc}
\hline & Estimate & Standard Error & p-value \\
\hline Technique & 0.8537 & 0.6769 & 0.2115 \\
Age & 0.0509 & 0.0829 & 0.5415 \\
Gender & 0.1757 & 0.4570 & 0.7019 \\
\hline
\end{tabular}

demonstrated a day effect with statistically significant lower pain scores for both study groups by POD 3 and onward compared to POD 0 as shown in Table 6 and represented graphically by average pain score in Figure 2.

A multivariate analysis of pain medications did demonstrate a difference with regards to tonsillectomy technique, but there was no difference appreciated in regards to age or gender as presented in Table 7 . After excluding 16 observations secondary to missing values, a repeated measures analysis exhibited a statistically significant increase in pain medications for both study groups on POD 1 and 2 but a significant decrease in medications beginning POD 7 compared to POD 0 as presented in Table 8 and graphically by average pain medications taken in Figure 3.

Although the coblator arm appeared to exhibit a steeper decrease in pain scores analysis ( -2.28 vs -1.34$)$ and medications $(-1.31$ vs -0.95$)$ compared to the electrocautery arm between POD 7 and 14, this was not considered statistically significant on repeated measures analysis ( $\mathrm{p}=0.1871$ and $\mathrm{p}=0.3686$, respectively).

The only statistically significant difference in survey responses was at baseline, where Coblation ${ }^{\circledR}$ patients reportedly exhibited improved liquid intake than electrocautery patients. There was no difference in the amount of food consumed, type of food texture, amount of conversing, activity level, or overall mood observed at baseline. Table 9 presents these results below. After excluding a few subjects secondary to incomplete responses, it was noted that children's absence from school, work missed by the caregivers, and ability of the caregiver to accomplish the day's planned activities were relatively similar between the two groups at baseline. This is presented in Table 10. No appreciable difference in survey responses were observed during any other postoperative day.

Table 6. Repeated measures analysis for pain scores.

\begin{tabular}{cccc}
\hline $\begin{array}{c}\text { Cautery and } \\
\text { Coblation }^{\circledR}\end{array}$ & Estimate & $\begin{array}{c}\text { Standard } \\
\text { Error }\end{array}$ & p-value \\
\hline Day 0 & - & - & - \\
Day 1 & 0.2211 & 0.3450 & 0.5237 \\
Day 2 & -0.3614 & 0.3888 & 0.3556 \\
Day 3 & -1.1054 & 0.3959 & 0.0067 \\
Day 5 & -1.8285 & 0.4959 & 0.0004 \\
Day 7 & -2.4222 & 0.4959 & $<0.0001$ \\
\hline
\end{tabular}

Table 7. Multivariate analysis of pain medications.

\begin{tabular}{cccc}
\hline & Estimate & Standard Error & p-value \\
\hline Technique & 1.4756 & 0.3626 & 0.0001 \\
Age & 0.0621 & 0.0491 & 0.2099 \\
Gender & -0.2159 & 0.2704 & 0.4273 \\
\hline
\end{tabular}




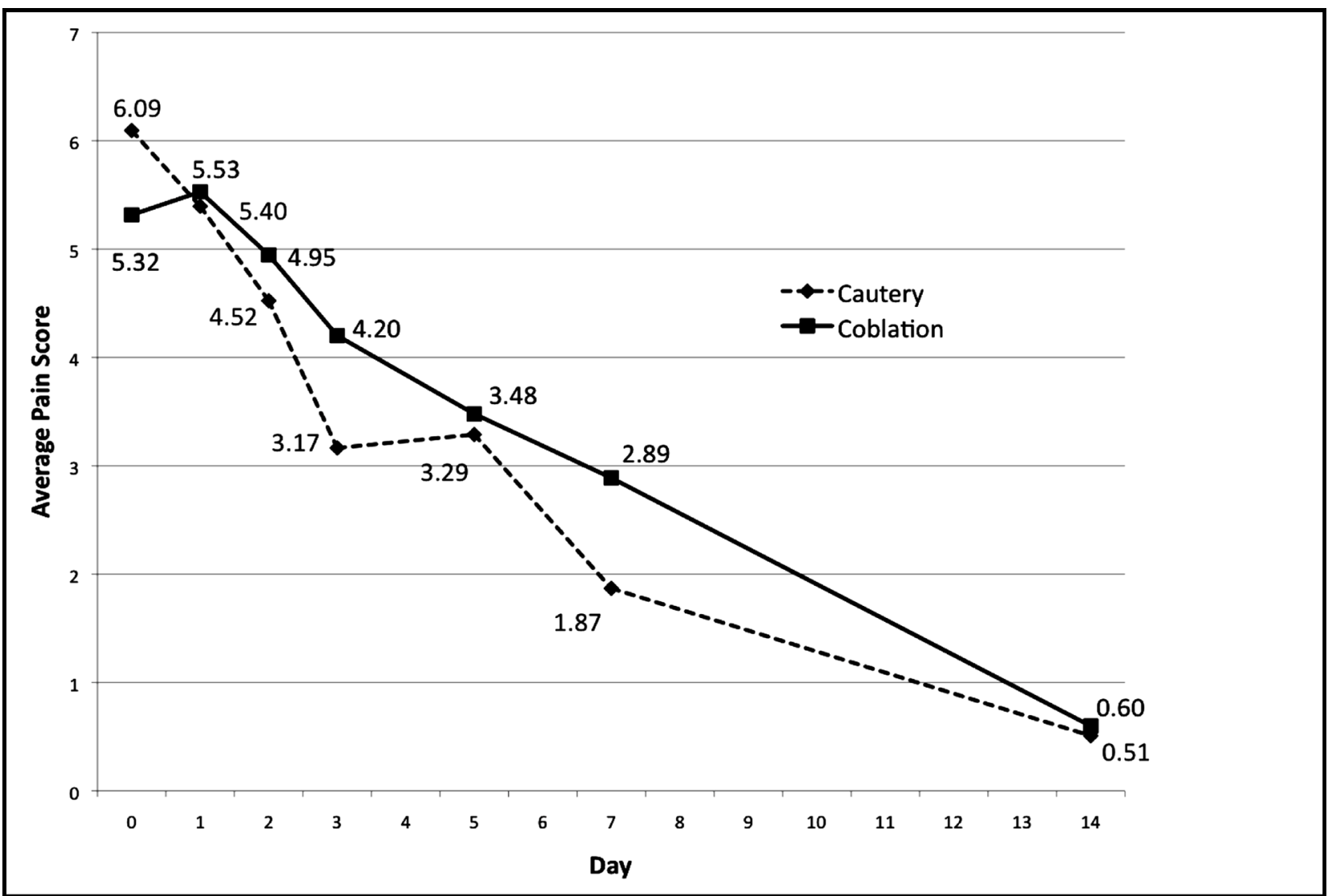

Figure 2. Average pain scores. Note almost identical pain scores and gradual decrease in pain score over time.

Table 8. Repeated measures analysis for pain medications administered.

\begin{tabular}{cccr}
\hline Cautery and Coblation $^{\circledR}$ & Estimate & Standard Error & p-value \\
\hline Day 0 & - & - & - \\
Day 1 & 1.3896 & 0.2127 & $<0.0001$ \\
Day 2 & 1.0976 & 0.2199 & $<0.0001$ \\
Day 3 & 0.1361 & 0.2393 & 0.5714 \\
Day 5 & -0.1823 & 0.2827 & 0.5211 \\
Day 7 & -0.6921 & 0.2676 & 0.0118 \\
\hline
\end{tabular}

Table 9. Baseline survey results (Part 1).

\begin{tabular}{cccc}
\hline SURVEY RESPONSES (mean, std dev) & CAUTERY $(\mathrm{n}=22)$ & COBLATION $(\mathrm{n}=52)$ & p-value \\
\hline Question 1 Child drinking? & $2.48(0.81)$ & $3.10(0.83)$ & 0.0049 \\
Question 2 Child eating? & $2.14(0.99)$ & $2.48(0.99)$ & 0.1880 \\
Question 3 Food texture? & $2.59(0.73)$ & $2.62(0.73)$ & 0.9063 \\
Question 4 Child talking? & $2.55(0.74)$ & $2.94(0.88)$ & 0.0820 \\
Question 5 Child active? & $2.95(1.21)$ & $3.08(1.16)$ & 0.6819 \\
Question 6 Child playing? & $2.18(1.40)$ & $2.24(1.17)$ & 0.6477 \\
Question 7 Child's mood? & $2.45(1.01)$ & $2.80(1.07)$ & 0.1692 \\
\hline
\end{tabular}




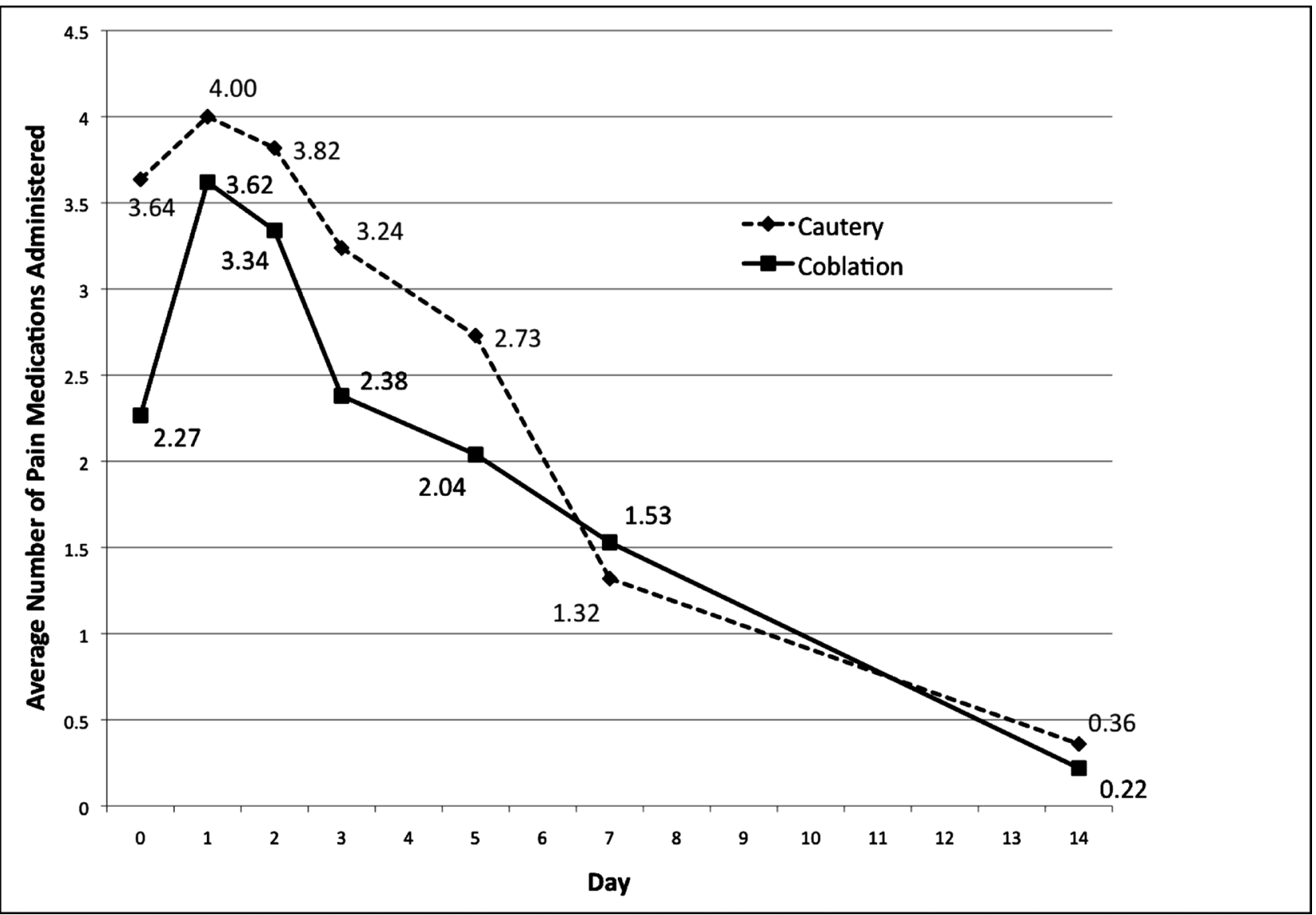

Figure 3. Average number of pain medications administered.

Table 10. Baseline survey results (Part 2).

\begin{tabular}{|c|c|c|c|}
\hline SURVEY RESPONSES (mean, std dev) & CAUTERY $(\mathrm{n}=22)$ & COBLATION $(\mathrm{n}=52)$ & p-value \\
\hline \multicolumn{4}{|l|}{ Question 8 Missing school? } \\
\hline Yes & $9(69.2 \%)$ & $23(57.5 \%)$ & \multirow[b]{2}{*}{0.4525} \\
\hline No & $4(30.8 \%)$ & 17 (42.5\%) & \\
\hline Not applicable (excluded) & 8 & 11 & \\
\hline \multicolumn{4}{|l|}{ Question 9 Parents missed work? } \\
\hline Yes & $8(57.1 \%)$ & $24(64.9 \%)$ & \multirow{2}{*}{0.6107} \\
\hline No & $6(42.9 \%)$ & $13(35.1 \%)$ & \\
\hline Not applicable (excluded) & 8 & 14 & \\
\hline \multicolumn{4}{|l|}{ Question 10 Able to complete day’s activities? } \\
\hline Yes or Some & $5(50.0 \%)$ & $20(76.9 \%)$ & \multirow[b]{2}{*}{0.2240} \\
\hline No & $5(50.0 \%)$ & $6(23.1 \%)$ & \\
\hline Not applicable (excluded) & 12 & 24 & \\
\hline
\end{tabular}

Complications included one patient from the Coblation ${ }^{\circledR}$ group admitted for dehydration and one patient from the electrocautery group who developed an allergic rash with amoxicillin. There were no post-tonsillectomy 
hemorrhages reported in either group.

\section{Discussion}

Although there were statistically significant results to support decreased pain medication use and improved oral intake of fluids with the Coblation ${ }^{\circledR}$ group on POD 0, the bulk of the data acquired from this study suggest that postoperative outcomes in children undergoing AT were similar regardless of which technique was employed. Just as important, there was no occurrence of increased postoperative hemorrhage reported in either group.

These results are similar to those attained by Parker et al., who noted decreased pain medication use in children undergoing coblator tonsillectomies only at twelve hours postoperatively but no difference in diet. The comparison group, however, conducted tonsillectomies via cold dissection with bipolar electrocautery for hemostasis [3]. When comparing coblator tonsillectomies with those performed with monopolar electrocautery, Chang et al. observed decreased pain medication use on POD 5, but there was also an improved oral intake and activity level [8]. Although the two study arms were different from each other only on POD 0, our study supported a statistically significant decrease in pain medications consumed by POD7 when compared to POD0 on repeated measures analysis. This was independent of the technique utilized.

Multivariate analysis revealed a statistically significant difference between the Coblation ${ }^{\circledR}$ and electrocautery study arms in regards to the amount of pain medication administered. It was noted that the two groups exhibited a similar presentation from POD 1 through 14. The only difference was on POD 0, and may attribute to the difference on multivariate analysis. A true difference cannot be excluded, secondary to dropout, as other studies have shown a decrease in post-operative narcotic use, leading to shortened recovery times and quicker return to normal activities [24]. However, less thermal damage has been observed with coblator tonsillectomies compared to monopolar electrocautery ones despite no difference in pain, diet, activity, or return to work [13], and this may explain the increase in pain medications given without an associated difference in pain scores observed in this study. It is conceivable that a relative increase in adjacent tissue damage with electrocautery dissection may lead to increased local edema and induce a globus sensation or discomfort that children perceive as pain and subsequently request for more medication.

This prospective trial sought to evaluate a disparity in postoperative outcomes in children undergoing AT with either Coblation ${ }^{\circledR}$ or electrocautery. Aside from minor differences in pain medication use and fluid intake on the day of surgery, it would appear that there is likely no significant difference in results between the two tech- niques. As such, an argument could be made that the choice of technique is best left to surgeon preference providing that the procedure is performed safely, competently, and in the best interest of the patient.

\section{Acknowledgements}

For assistance in developing a standardized anesthesia protocol

1) Amr Abouleish, MD, MBA

2) Joaquin Cortiella, MD, MPH

3) Marvin Cohen, MD

For tireless assistance in statistical analysis

1) Gwen Baillargeon, MS

\section{REFERENCES}

[1] B. R. Maddern, "Electrosurgery for Tonsillectomy,” Laryngoscope, Vol. 112, No. S100, 2002, pp. 11-13. http://dx.doi.org/10.1002/lary.5541121405

[2] E. A. Magdy, S. Elwany, A. S. El-Daly, et al., "Coblation Tonsillectomy: A Prospective, Double-Blind, Randomized, Clinical and Histopathological Comparison with Dissection-Ligation, Monopolar Electrocautery and Laser Tonsillectomies,” The Journal of Laryngology \& Otology, Vol. 122, No. 3, 2008, pp. 282-290. http://dx.doi.org/10.1017/S002221510700093X

[3] N. P. Parker and D. L. Walner, "Post-Operative Pain Following Coblation or Monopolar Electrocautery Tonsillectomy in Children: A Prospective, Single-Blinded, Randomised Comparison," Clinical Otolaryngology, Vol. 36, No. 5, 2011, pp. 468-474. http://dx.doi.org/10.1111/j.1749-4486.2011.02384.x

[4] Y. L. Wilson, D. M. Merer and A. L. Moscatello, "Comparison of Three Common Tonsillectomy Techniques: A Prospective Randomized, Double-Blinded Clinical Study,” Laryngoscope, Vol. 119, No. 1, 2009, pp. 162-170. http://dx.doi.org/10.1002/lary.20024

[5] M. S. Timms and R. H. Temple, "Coblation Tonsillectomy: A Double-Blind Randomized Controlled Study,” The Journal of Laryngology \& Otology, Vol. 116, No. 6, 2002, pp. 450-452. http://dx.doi.org/10.1258/0022215021911031

[6] R. H. Temple and M. S. Timms, "Pediatric Coblation Tonsillectomy," International Journal of Pediatric Otorhinolaryngology, Vol. 61, No. 3, 2001, pp. 195-198. http://dx.doi.org/10.1016/S0165-5876(01)00553-5

[7] K. E. Stoker, D. M. Don, D. R. Kang, et al., "Pediatric Total Tonsillectomy Using Coblation Compared to Conventional Electrosurgery: A Prospective, Controlled Single-Blind Study," Otolaryngology-Head and Neck Surgery, Vol. 130, No. 6, 2004, pp. 666-675. http://dx.doi.org/10.1016/j.otohns.2004.02.012

[8] K. W. Chang, "Randomized Controlled Trial of Coblation versus Electrocautery Tonsillectomy,” OtolaryngologyHead and Neck Surgery, Vol. 132, No. 2, 2005, pp. 273280. http://dx.doi.org/10.1016/j.otohns.2004.11.002

[9] S. P. Parsons, S. R. Cordes and B. Comer, "Comparison 
of Posttonsillectomy Pain Using the Ultrasonic Scalpel, Coblator, and Electrocautery,” Otolaryngology-Head and Neck Surgery, Vol. 134, No. 1, 2006, pp. 106-113. http://dx.doi.org/10.1016/j.otohns.2005.09.027

[10] S. Mitic, M. Tvinnereim, E. Lie and B. J. Saltyte, “A Pilot Randomized Controlled Trial of Coblation Tonsillectomy versus Dissection Tonsillectomy with Bipolar Diathermy Haemostasis,” Clinical Otolaryngology, Vol. 32, No. 4, 2007, pp. 261-267. http://dx.doi.org/10.1111/j.1365-2273.2007.01468.x

[11] L. Di Rienzo Businco and G. Coen Tirelli, "Paediatric Tonsillectomy: Radiofrequency-Based Plasma Dissection Compared to Cold Dissection with Sutures," Acta Otorhinolaryngologica Italica, Vol. 28, No. 2, 2008, pp. 6772.

[12] V. K. Paramasivan, S. V. Arumugam and M. Kameswaran, "Randomised Comparative Study of Adenotonsillectomy by Conventional and Coblation Method for Children with Obstructive Sleep Apnea," International Journal of Pediatric Otorhinolaryngology, Vol. 76, No. 6, 2012, pp. 816-821. http://dx.doi.org/10.1016/j.ijporl.2012.02.049

[13] U. K. Shah, J. Galinkin, R. Chiavacci and M. Briggs, "Tonsillectomy by Means of Plasma-Mediated Ablation," Otolaryngology-Head and Neck Surgery, Vol. 128, No. 6, 2002, pp. 672-676. http://dx.doi.org/10.1001/archotol.128.6.672

[14] N. L. Shapiro and N. Bhattacharyya, "Cold Dissection versus Coblation-Assisted Adenotonsillectomy in Children,” Laryngoscope, Vol. 117, No. 3, 2007, pp. 406-410. http://dx.doi.org/10.1097/MLG.0b013e31802ffe47

[15] D. Parker, L. Howe, V. Unsworth and R. Hilliam, “A Randomized Controlled Trial to Compare Postoperative Pain in Children Undergoing Tonsillectomy Using Cold Steel Dissection with Bipolar Hemostasis versus Coblation Technique," Clinical Otolaryngology, Vol. 34, No. 3, 2009, pp. 225-231. http://dx.doi.org/10.1111/j.1749-4486.2009.01932.x

[16] N. Gustavii, M. Bove and C. Dahlin, "Postoperative Morbidity in Traditional versus Coblation Tonsillectomy," Annals of Otology, Rhinology \& Laryngology, Vol. 119,
No. 11, 2010, pp. 755-760.

[17] D. T. Jones, M. A. Kenna, J. Guidi, et al., "Comparison of Postoperative Pain in Pediatric Patients Undergoing Coblation Tonsillectomy versus Cautery Tonsillectomy," Otolaryngology_Head and Neck Surgery, Vol. 144, No. 6, 201, pp. 972-7.

[18] A. P. Noon and S. Hargreaves, "Increased Post-Operative Hemorrhage Seen in Adult Coblation Tonsillectomy," The Journal of Laryngology \& Otology, Vol. 117, No. 9, 2003, pp. 704-706. http://dx.doi.org/10.1258/002221503322334521

[19] A. Belloso, A. Chidambaram, P. Morar and M. S. Timms, "Coblation Tonsillectomy versus Dissection Tonsillectomy: postoperative Hemorrhage,” Laryngoscope, Vol. 113, No. 11, 2003, pp. 2010-2013. http://dx.doi.org/10.1097/00005537-200311000-00029

[20] D. Lowe and J. van der Meulen, "National Prospective Tonsillectomy Audit. Tonsillectomy Technique as a Risk Factor for Postoperative Hemorrhage,” Lancet, Vol. 364, No. 9435, 2004, pp. 697-702. http://dx.doi.org/10.1016/S0140-6736(04)16896-7

[21] V. Divi and M. Benninger, "Postoperative Tonsillectomy Bleed: Coblation versus Noncoblation,” Laryngoscope, Vol. 115, No. 1, 2005, pp. 31-33. http://dx.doi.org/10.1097/01.mlg.0000150682.62517.0e

[22] M. J. Burton and C. Doree, "Coblation versus Other Surgical Techniques for Tonsillectomy," Cochrane Database of Systematic Reviews, Vol. 18, 2007, Article ID: CD004619.

[23] H. M. Myatt and R. A. Myatt, "The Development of a Pediatric Quality of Life Questionnaire to Measure PostOperative Pain Following Tonsillectomy,” International Journal of Pediatric Otorhinolaryngology, Vol. 44, No. 2, 1998 , pp. $115-123$. http://dx.doi.org/10.1016/S0165-5876(98)00053-6

[24] M. Benninger and D. Walner, "Coblation: Improving Outcomes for Children Following Adenotonsillectomy," Clinical Cornerstone, Vol. 9, Suppl. 1, 2007, pp. S13-23. http://dx.doi.org/10.1016/S1098-3597(07)80005-6 


\section{Appendix: Anesthesia Protocol}

\section{Preoperatively}

1) NPO orders: standard orders for DSU patients

a) Clear liquids 2 hrs

b) All else midnight

c) If less <6 months different, but should not be an issue for this surgery

2) Premedication: standard orders for DSU patients

a) All patients, even those with diagnosis of sleep apnea

b) on call to OR (approximately 30-40 min before induction)

c) midazolam po $0.5 \mathrm{mg} / \mathrm{kg}$ max $20 \mathrm{mg}$

d) acetominaphen po $15 \mathrm{mg} / \mathrm{kg} \max 320 \mathrm{mg}$ (10 ml)

\section{Anesthesia Care}

3) Mask Induction with $8 \%$ sevoforane and $70 \%$ nitrous oxide

4) After induction, IV started.

5) To facilitate intubation, Propofol IV $1 \mathrm{mg} / \mathrm{kg}$ single dose.

6) Intubation with oral Rae cuffed endotracheal tube

7) IV Medications given immediately after intubation

a) Fentanyl $1 \mathrm{mcg} / \mathrm{kg}$

b) Odansetron $0.150 \mathrm{mg} / \mathrm{kg}$ up to $4.0 \mathrm{mg}$

c) Dexamethasone $0.50 \mathrm{mg} / \mathrm{kg}$ up to $10.0 \mathrm{mg}$

8) Maintenance with $2 \%$ Isoforane and $70 \%$ Nitrous Oxide
9) After procedure begin, allow patient to spontaneously breath adjusting Isoforane for End-Tidal CO2 between 50-59

10) IV fluids. Replacement of at least half of deficit as calculated by 4-2-1 rule and hours NPO. This half should be given in first half hour.

11) Extubate awake

\section{Immediate Postoperative Management}

12) Naseau and vomiting. One dose, if needed, Odansetron $0.150 \mathrm{mg} / \mathrm{kg}$ up to $4.0 \mathrm{mg}$. If needs additional medication, leave study.

13) IV fluids. Per routine ENT orders

14) PO fluids: unlimited clear liquids as tolerated.

15) Emergence delirium and pain management in first 30 minutes

a) If meets FACES scale $>4$

(1) First dose: Dexamedetomidine $0.5 \mathrm{mcg} / \mathrm{kg} \mathrm{IV}$

(2) Second dose after 5 minutes and FACES scale $>4$ : Morphine $0.025 \mathrm{mg} / \mathrm{kg}$ IV

16) Pain management from $30 \mathrm{~min}$ to $90 \mathrm{~min}$,

a) FACES Scale $>4$

b) Morphine $0.025 \mathrm{mg} / \mathrm{kg}$ IV q10 min prn, max total dose of $1.0 \mathrm{mg} / \mathrm{kg}$

c) Additional medication needed, leave study.

17) Keep patients in PACU at least 90 minutes

a) Assure that immediate pain management is consistent for the first 90 minutes

Document when meets discharge criteria 